\title{
Effect of the addition of flavan-3-ols on the HPLC-DAD salivary-protein profile
}

\author{
Natalia Quijada-Morín, Carlos Crespo-Expósito, Julián C. Rivas-Gonzalo, Ignacio García-Estévez, \\ María Teresa Escribano-Bailón*

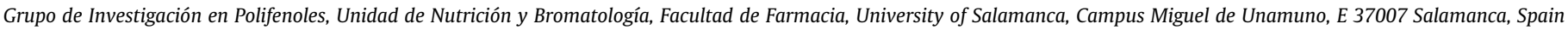

\section{A R T I C L E I N F O}

\section{Article history:}

Received 17 November 2015

Received in revised form 28 March 2016

Accepted 30 March 2016

Available online 30 March 2016

\section{Keywords:}

Flavan-3-ol

Salivary protein

Astringency

Soluble aggregates

HPLC-DAD

\begin{abstract}
A B S T R A C T
The interaction between monomeric flavan-3-ols and salivary proteins has been studied using HPLC-DAD. A chromatographic method has been described and seven protein fractions were collected. The peptides and proteins present in each fraction have been identified using nLC-MS-MS analysis. The interaction between saliva and catechin, epicatechin and gallocatechin has been studied. These compounds interact in a discriminated way with salivary proteins: catechin causes a decrease of some fractions, epicatechin causes the decrease or increase of fractions while gallocatechin seems to cause an increase of two fractions. This variable behavior is explained, for the decrease in the chromatographic area, by the precipitation of salivary proteins and, for the increase of the area, by the formation of soluble complexes and/or for the formation of new peaks.
\end{abstract}

(c) 2016 Elsevier Ltd. All rights reserved.

\section{Introduction}

Saliva is an exocrine secretion produced by salivary glands present in mouth whose main function is to lubricate the oral cavity. It is mainly composed by water, electrolytes, proteins, glycoproteins, glycolipids, carbohydrates and serum transudates (Wu, Csako, \& Herp, 1994).

Salivary proteins have been classified in seven groups attending to their structure and characteristics (Castagnola, Cabras, Vitali, Sanna, \& Messana, 2011), histatins, statherin, cystatins, prolinerich proteins (PRPs), mucins, $\alpha$-amylase and carbonic anhydrases. PRPs are also divided into acidic PRPs (aPRPs), basic PRPs (bPRPs) and glycosylated PRPs (gPRPs).

Flavan-3-ols are a wide family of phenolic compounds present in many foods and beverages, such as fruits, wine and beer. In red wine they are present as oligomers or polymers of four main flavan-3-ols, namely catechin, epicatechin, gallocatechin and epigallocatechin (Monagas, Gómez-Cordovés, Bartolomé, Laureano, \& Ricardo-Da-Silva, 2003). The presence of different linkage positions, galloylation, and combinations between these four subunits make this group have a great number of compounds.

Flavan-3-ols, primarily oligomers and polymers (Chira, Schmauch, Saucier, Fabre, \& Teissedre, 2009; Peleg, Gacon,

\footnotetext{
* Corresponding author.

E-mail addresses: nataliaquijada@usal.es (N. Quijada-Morín), carlos.crespo@ usal.es (C. Crespo-Expósito), jcrivas@usal.es (J.C. Rivas-Gonzalo), igarest@usal.es (I. García-Estévez), escriban@usal.es (M.T. Escribano-Bailón).
}

Schlich, \& Noble, 1999), have been broadly associated to the astringency perception of food and beverages, mainly related to their ability to precipitate proteins, which is one of the mechanisms commonly accepted for explaining the development of the astringency (de Freitas \& Mateus, 2012; Scollary, Pasti, Kallay, Blackman, \& Clark, 2012).

The structure of proanthocyanidins has been related to their astringency properties. Regarding their size, some controversies are found in literature, it has been suggested that polymeric procyanidins (degree of polymerization from 12 to 34 ) show higher astringency intensity than the oligomeric ones (from 2 to 15) (Sun et al., 2013), and several authors have found a relationship between $\mathrm{mDP}$ and astringency (Chira et al., 2009; Peleg et al., 1999); while others did not find a significant influence of mDP on the astringency perception (Wollmann \& Hofmann, 2013).

The stereochemistry of flavan-3-ols has also shown to influence their mouthfeel, being (-)-epicatechin more bitter and more astringent than (+)-catechin (Ferrer-Gallego, Hernández-Hierro, Rivas-Gonzalo, \& Escribano-Bailón, 2014; Kallithraka, Bakker, \& Clifford, 1997; Thorngate \& Noble, 1995).

Regarding the influence of the flavan-3-ols structure on their ability to bind proteins, several studies have pointed out that the flavan-3-ol concentration is important for the interaction, since flavan-3-ols can arrange on micellar structures that would decrease their interaction with salivary proteins (Cala et al., 2012). Moreover, their size and possibility of present 
intramolecular П-П stacking is also important for the interaction with salivary proteins (Cala et al., 2011, 2010).

Astringency is described as the puckering, hardness, roughness and dryness sensations perceived in mouth after the ingestion of several food and beverages, such as red wine, tea or unripen fruits (Jiang, Gong, \& Matsunami, 2014). The mechanisms that drive this sensation are not totally known but the interaction with salivary proteins causing its precipitation seems to be one of the most important ones (de Freitas \& Mateus, 2012; Ma et al., 2014). Furthermore, in the last years other mechanisms such as interaction with receptors (Schwarz \& Hofmann, 2008), the presence of colloidal particles in solution (Cala et al., 2010) or salivary film disruption (Gibbins \& Carpenter, 2013) have also been proposed.

Astringency is an important organoleptic characteristic that is closely related to red wine quality; it is commonly acknowledged that high quality red wines must present a balanced astringency (Gawel, 1998). The evaluation of the astringency has been classically made by tasting panels, although it has several inconveniences such as the difficulty to join a reliable panel. Indirect methods to evaluate astringency are mainly focused on the evaluation of protein precipitation, due to the fact that this has been considered as the main mechanism driving astringency. Despite the evaluation of protein precipitation methods have been widely used, they present the inconvenience of the lack of information of other mechanisms which are involved in astringency development, which are not evaluated with those methods and also the absence of information of the astringency subqualities which could be both pleasant or unpleasant (Ferrer-Gallego, Gonçalves, Rivas-Gonzalo, Escribano-Bailón, \& de Freitas, 2012), and their persistence. In the last years, the existence of soluble complexes between some of these proteins and flavan-3-ols has been demonstrated using HPLC (Kallithraka, Bakker, \& Clifford, 1998) and also SDS-PAGE (Sarni-Manchado, Canals-Bosch, Mazerolles, \& Cheynier, 2008) and there is an increasing interest in their study as they could be an intermediary state in the formation of insoluble complexes and also affect the astringency development.

The astringency of different flavan-3-ols have been recently investigated and it has been stated the importance of the structure and the stereochemistry of flavanols in the development of different sub-qualities. The presence of two or three hydroxyl groups in $B$ ring seemed to be decisive in the development of negative sensory attributes such as dry, rough and unripe, which are more related to dihydroxylated compounds whereas trihydroxylated compounds are more related to velvety, viscosity and smoothness, which are considered as positive attributes (Ferrer-Gallego et al., 2015). Moreover, studies involving sensory evaluation have demonstrated that $(+)$-catechin is perceived as less astringent and bitter than its isomer (-)-epicatechin (Peleg et al., 1999), which suggests that the stereochemistry plays an important role in astringency development.

The aim of this study was to go deeper into the knowledge of the interactions between flavanols and salivary proteins and to determine if the sensations elicited by flavanols, possessing stereochemical and structural differences, are related to different chromatographic protein profiles after incubation of salivary proteins with flavanols. To do this, an analytical method to determine salivary proteins using HPLC-DAD has been established and the variations occurred in the different protein fractions, caused by interaction with flavanolic compounds, has been estimated.

\section{Materials and methods}

\subsection{Saliva collection and treatment}

Eight healthy, non-smoker volunteers (four men and four women) were selected for this study. Whole saliva (WS) was collected around 10:30 am in order to avoid variations due to circadian rhythms of salivary protein secretion (Dawes, 1972). TFA was immediately added to inhibit intrinsic protease activity and to precipitate high molecular weight salivary proteins such as mucins, $\alpha$-amylase, carbonic anhydrase and lactoferrin, while other salivary proteins remain soluble and can be directly analyzed by HPLC-DAD (Messana et al., 2004; Soares et al., 2011). The sample was centrifuged for $10 \mathrm{~min}$ at $12,000 \mathrm{~g}$ and submitted to dialysis using a Spectra/Por ${ }^{\circledR} 3$ cellulose membrane (SpectrumLabs) with an exclusion size of $3.5 \mathrm{kDa}$. Saliva was dialyzed against ultrapure water at $10^{\circ} \mathrm{C}$ for $48 \mathrm{~h}$, and the dialysis medium was renewed after $8 \mathrm{~h}$ of contact with the membrane. Dialysis process provoked the elimination of electrolytes and improved the HPLC-DAD separation. Treated saliva (TS) was frozen prior to its use in the interaction assays.

The study complies with the polices laid down by the Helsinki declaration and it was approved by the Bioethics Committee of the University of Salamanca

\subsection{Chemicals}

All solvents were HPLC grade and all chemicals were analytical grade. Catechin (CAT), epicatechin (EC), gallocatechin (GC), ammonium bicarbonate, iodoacetamide (IAA), and dithiothreitol (DTT) were purchased from Sigma-Aldrich (Saint Louis, MO, USA). Endoproteinase Lys- $C$ as purchased from Wako Chemicals USA, Inc., and trypsin from Promega Corporation (Madison, WI, USA). Ultrapure water was obtained from a Milli-Q Gradient water purification system (Millipore, Billerica, MA, USA).

\subsection{Interaction assays}

$150 \mu \mathrm{L}$ of TS was mixed with $150 \mu \mathrm{L}$ of the flavan-3-ol solution and kept at room temperature. Two different concentrations of flavan-3-ols and times of interaction were assayed, corresponding to $0.5 \mathrm{~g} \mathrm{~L}^{-1}$ and $1 \mathrm{~g} \mathrm{~L}^{-1}$ and to $30 \mathrm{~min}$ and $2 \mathrm{~h}$. Samples were filtrated through $0.45 \mu \mathrm{m}$ filters and submitted to chromatographic analysis immediately to their preparation. All the experiments were performed in triplicate.

\subsection{HPLC analysis}

Agilent 1200 Series HPLC system (Agilent Technologies, Palo Alto, CA, USA) consisting of an autosampler, a quaternary pump, a vacuum degasser, a thermostated column compartment and a diode array detector (DAD) that were controlled by ChemStation software (version B.04.01; Agilent Technologies) was used for chromatographic analyses. The chromatographic separation was performed on a Zorbax 300SB-C8, $5 \mu \mathrm{m}(2.1 \times 150 \mathrm{~mm})$ column, mobile phases were aqueous TFA $0.1 \%$ (A) and TFA $0.1 \%$ in acetonitrile (B). The elution profile was as follows: $8-12 \%$ B in $10 \mathrm{~min}, 12-32 \% \mathrm{~B}$ in $50 \mathrm{~min}$ followed by the washing and re-equilibration of the column to initial conditions. The flow rate was set at $0.3 \mathrm{~mL} \mathrm{~min}^{-1}$ and the injection volume was $90 \mu \mathrm{L}$.

Preferred detection wavelengths were $214 \mathrm{~nm}$ for protein detection and $280 \mathrm{~nm}$ for flavan-3-ols detection.

\subsection{Peptide fractionation and identification}

Seven protein fractions were collected after HPLC-DAD separation in the conditions previously described using a Waters fraction automatic collector connected to the outlet of the DAD-cell.

The fractions were freeze dried using a Telstar Cryodos-80 and the peptides present in each fraction were identified after tryptic digestion and nLC-MS-MS analysis. Digestion was performed as described in (Link et al., 1999) with modifications as follows. 
Lyophilized proteins were resolubilized in $8 \mathrm{M}$ urea/50 $\mathrm{mM} \mathrm{NH}_{4}$ $\mathrm{HCO}_{3}$, reduced and alkylated using $100 \mathrm{mM}$ DTT and $200 \mathrm{mM}$ IAA, then $100 \mathrm{mM}$ DTT was added to quench unreacted IAA. Endoproteinase Lys- $C$ was added to a final substrate-to-enzyme ratio of $100: 1$, and the reaction was incubated at $37^{\circ} \mathrm{C}$ for $4 \mathrm{~h}$. The Lys-C digestion was diluted four fold with $50 \mathrm{mM} \mathrm{NH} \mathrm{NHCO}_{3}$, and modified trypsin was added to a final substrate-to-enzyme ratio of 50:1. The trypsin digestion was incubated at $37^{\circ} \mathrm{C}$ for $16 \mathrm{~h}$.

Purification of tryptic peptides was performed with C18 Stagetips and an aliquot (1/20) of the sample containing the generated tryptic peptides was diluted in $5 \mu \mathrm{L}$ of $0.5 \%$ formic acid/ACN (97/3), prior to analysis by nLC-MS/MS.

A nano-UPLC system (nanoAcquity, Waters Corp., Milford/MA, USA) coupled to a LTQ-Orbitrap Velos mass spectrometer (Thermo Fisher Scientific, San Jose/CA, USA) via a nano-electrospray ion source (NanoSpray flex, Proxeon, Thermo) was used for reversedphase LC-MS/MS analysis. Chromatographic conditions were as follows: column nanoACQUITY UPLC BEH $1.7 \mu \mathrm{m}, 130 \AA$, $75 \mu \mathrm{m} \times 250 \mathrm{~mm} \mathrm{C18}$ (Waters Corp.), flow rate of $250 \mathrm{~nL} \mathrm{~min}^{-1}$, gradient A: formic acid $0.5 \%$, and B: ACN, from 3 to $45 \%$ B in $60 \mathrm{~min}$.

The LTQ-Orbitrap Velos was operated in the positive ion mode applying a data-dependent automatic switch between survey MS scan and tandem mass spectra (MS/MS) acquisition. Survey scans were acquired in the mass range of $m / z \quad 400-1600$ with 60,000 resolution at $\mathrm{m} / \mathrm{z} 400$ with lock mass option enabled for the 445.120025 ion (Olsen et al., 2005). MASCOT (Perkins, Pappin, Creasy, \& Cottrell, 1999) search algorithm was used for searching the acquired MS/MS spectra, using Thermo Scientific Proteome Discoverer software (v. 1.4.1.14) against a SwissProt_20150126 database for Homo sapiens sequences. Search parameters were as follows: semi-trypsin digestion with up to two missed cleavages, $10 \mathrm{ppm}$ and $0.8 \mathrm{Da}$ mass tolerances for precursor and product ions, respectively, oxidation of methionine was established as variable modification and carbamidomethylation of cysteine as fixed modification. Peptides having MASCOT scores of less than 20 were not considered for analysis. One percent false discovery rate using Percolator (Brosch, Yu, Hubbard, \& Choudhary, 2009) was used for peptide validation.

\subsection{Statistical analysis}

Analysis of variance (ANOVA) and post-hoc Tukey HSD test were performed using the software packing for Windows IBM SPSS 21 (SPSS, Inc., Chicago, IL, USA). The confidence level for the post-hoc Tukey HSD was set at $95 \%$.

\section{Results and discussion}

\subsection{Identification of peptides present in each fraction}

The chromatographic conditions were optimized in order to obtain a salivary profile which was repetitive among days and which allowed a quite good separation of the different salivary proteins during the chromatographic run (Fig. 1). The obtained profile is in good agreement with those reported in previous works (Cabras et al., 2009; Soares et al., 2011).

The chromatographic conditions used allowed the separation of the salivary peptides in seven fractions according to their retention time (Fig. 1), which were collected at the DAD-detector outlet. Fraction 1 was collected from 16.5 to $22.5 \mathrm{~min}$, fraction 2 from 22.5 to $25.9 \mathrm{~min}$, fraction 3 from 25.9 to $29.1 \mathrm{~min}$, fraction 4 from 30.6 to $34.5 \mathrm{~min}$, fraction 5 from 37.8 to $42.0 \mathrm{~min}$, fraction 6 from 49.5 to $51.8 \mathrm{~min}$, fraction 7 from 54.4 to $57.9 \mathrm{~min}$. The isolated fractions were freeze-dried prior to their identification.
Peptides were identified after tryptic digestion in the conditions previously described, nLC-MS-MS analysis and the comparison of the results with database SwissProt. The large quantity of proline present in the structure of salivary proteins does not allow the complete tryptic digestion of the samples, thus, for identification purposes, the peptides were considered as semi-tryptic peptides. The peptides identified in each fraction are summarized in Table 1. The peptide or protein marked in bold letters in Table 1 corresponds to the most abundant peptides in the corresponding fraction; their relative abundance in each fraction was estimated by using the emPAI index (Ishihama et al., 2005). bPRPs were eluted in the first fraction. Histatin 3 was identified in several fractions, which can be due to the presence in saliva of a high number of peptides derived from this protein as a result of the diversity of posttransductional modifications. These peptides present a variety of characteristics and thus made a difficult task the separation in only one fraction, while the separation of histatin 1 is more accurate, being found in fraction 5. P-B peptide is eluted with bPRPs and statherin. This peptide is often considered part of bPRPs family, but it also presents some similarity to statherin, being thus found in the same fractions that these proteins, mainly in fractions 1,3 and 7. gPRPs and aPRPs are eluted after bPRPs, in fractions 3 and 5 respectively, in good agreement with previous works which have used RP-HPLC to separate salivary proteins (Messana et al., 2004; Soares et al., 2011).

Cystatins were eluted in fraction 6; this group of proteins present a remarkable absorbance at $280 \mathrm{~nm}$ due to the presence of aromatic aminoacids in their structure when compared with other salivary proteins, which allowed the tentative identification of this fraction as cystatins regarding the HPLC-DAD profile. Statherin is the last protein to be eluted in the described conditions. This elution profile is in good agreement with those previously described in literature (Messana et al., 2004; Soares et al., 2011), and provides a quite good separation of the different protein groups.

\subsection{Interaction experiments}

The studied flavan-3-ols were injected individually in the same conditions to verify the absence of chromatographic interferences with the salivary proteins. The flavan-3-ols eluted during the first minutes of the chromatographic run and they did not interfere with the protein peaks.

\subsubsection{Catechin}

The addition of CAT to saliva clearly modified the chromatographic profile. No differences were shown for the two times evaluated (30 min and $2 \mathrm{~h}$ of interaction), which may indicate that the interaction of CAT and salivary proteins is completed in less than $30 \mathrm{~min}$ and once it is achieved, it remains stable. This is in good agreement with the previous molecular dynamics simulation experiments carried out by Ferrer-Gallego et al. (2015), who observed that the interaction of CAT and a model peptide (IB7 $\left.{ }_{14}\right)$ remained stable once it had occurred. As can be seen in Fig. 2, concentration affected the different fractions on a discriminated way. Fractions 3, 5 and 6 remained unchanged with the two different concentrations of CAT assayed. Fraction 1 showed a decrease on its area of similar intensity with both concentrations assayed, although these decreases are not statistically significant $(p<0.05)$. The chromatographic area of fraction 2 showed a decrease with the two concentrations of CAT assayed, being this decrease greater as the concentration of CAT is increased. Nevertheless, the change in the chromatographic area for the lower concentration of CAT assayed was not statistically significant compared with the control sample. This behavior could suggest that CAT is able to precipitate some protein or peptides present in fraction 2 (P-B peptide and/or histatin 3 derived peptides) and that the 


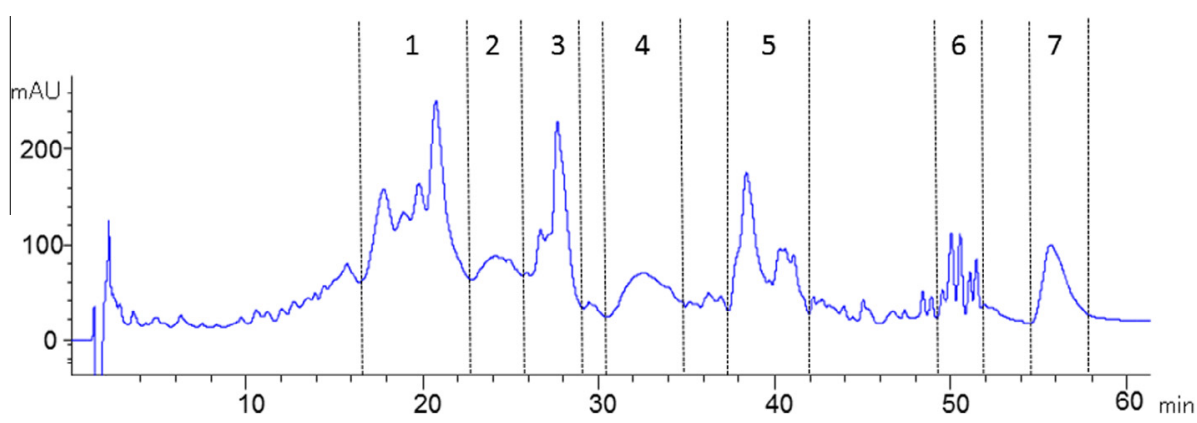

Fig. 1. Chromatogram registered at $214 \mathrm{~nm}$ of the treated saliva, marks for the seven collected fractions.

Table 1

Proteins and peptides identified in each fraction. Bold letters indicate the most abundant peptides in the fraction

\begin{tabular}{ll}
\hline Fraction & Peptides \\
\hline 1 & bPRP1; bPRP2; bPRP3; bPRP4 \\
& His-3 \\
& P-B peptide \\
2 & His-3 \\
& P-B peptide \\
& Glycosylated bPRP1; glycosylated bPRP2; glycosylated bPRP3 \\
3 & His-3 \\
& P-B peptide \\
4 & His-3 \\
5 & aPRP1/2 \\
& aPRP3/4 \\
& His-1 \\
6 & Cystatins \\
7 & Statherin \\
& P-B peptide \\
\hline
\end{tabular}

strength of the precipitation is related to CAT concentration. In the case of fraction 4 , a significant decrease in its chromatographic area was observed in the presence of the lower concentration of CAT while the higher one did not provoke a significant change. Fraction 7 presented a decrease which is dependent of the concentration of CAT assayed, despite the differences between the two concentrations assayed are not important enough to show statistical differences between them. As in the case of fraction 2, this behavior indicates that the interaction of the flavan-3-ol and the peptides in this fraction is concentration-dependent, suggesting that the higher the concentration of CAT, the higher the precipitation of proteins and thus, the astringency sensation developed.

The identification of the proteins and peptides present in each fraction reveals that the main proteins interacting with CAT are P-B peptide and/or statherin and also probably histatin 3 and bPRPs. The absence of signification and the scarce variation in the chromatographic profile of fractions mainly constituted by glycosylated bPRP, aPRP and cystatins (fractions 3, 5 and 6) could indicate that these protein fractions are not implicated in the interaction between catechin and proteins and therefore they should not be implicated in the development of the astringency sensation elicited by this flavanol.

\subsubsection{Epicatechin}

The addition of EC to salivary proteins provoked, on the salivary protein profile, different effect that the addition of CAT (Fig. 3). In this case, two fractions (fractions 1 and 2) showed significant increase in their area when EC is present in the medium, three fractions presented a significant decrease with the higher concentration of EC assayed (fractions 3, 5 and 7) and two fractions did not show significant changes (fractions 4 and 6). As in the case of CAT, no differences were found in the profile for the two times assayed ( $30 \mathrm{~min}$ and $2 \mathrm{~h}$, data not shown), which suggest that the interaction of EC and salivary proteins takes place in less than $30 \mathrm{~min}$ and this interaction is stable once it is reached.

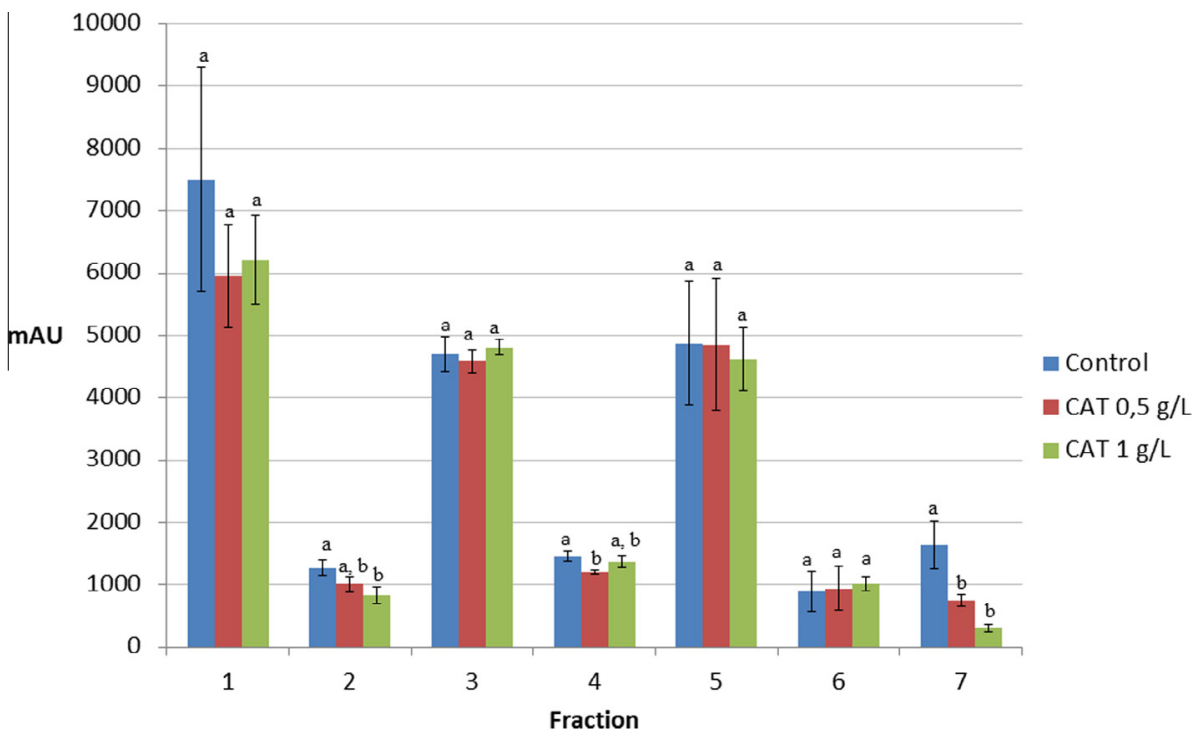

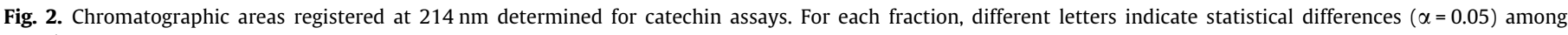
samples. 


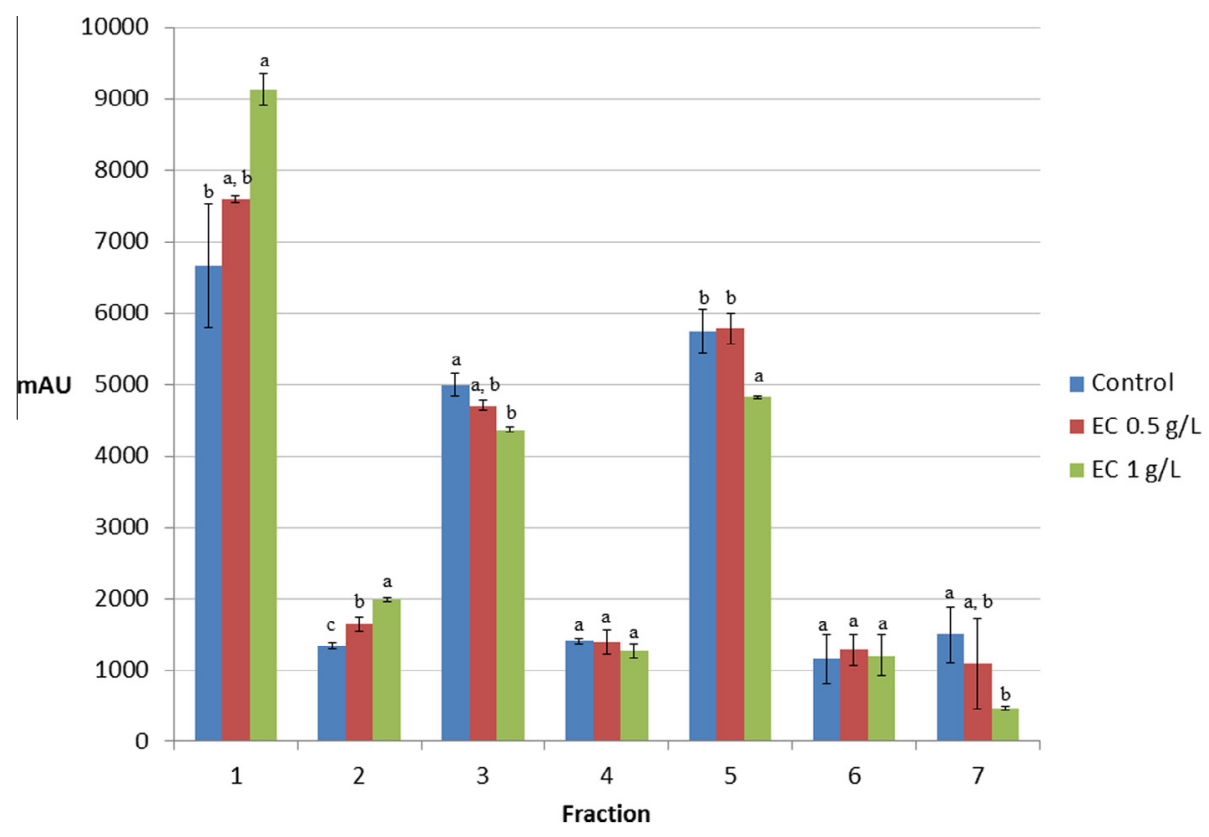

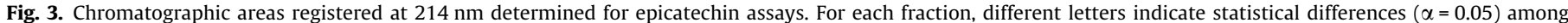
samples.

The statistical significant increases in the fractions 1 and 2 were accompanied with the appearance of new peaks in the chromatogram registered at $280 \mathrm{~nm}$ (maximum wavelength of flavanols). This suggests the formation of soluble complexes protein-EC, which would justify the increase of absorbance at $214 \mathrm{~nm}$ and the presence of new peaks at $280 \mathrm{~nm}$. Those new peaks were not detected when pure EC is analyzed in the same conditions. Hence it could be inferred that these peaks are due to the formation of soluble complexes between salivary proteins and EC. The formation of soluble complexes has been previously reported in the literature (Hagerman, 1992; Kallithraka et al., 1998; Perez-Maldonado, Norton, \& Kerven, 1995). Kallithraka et al. (1998) proposed that new peaks appearing in the chromatograms obtained after tasting of either wine or grape seed solutions were due to the formation of protein-phenol soluble complexes. The existence of soluble complexes had also been proved using SDS-PAGE experiments (Sarni-Manchado et al., 2008) and MALDI-TOF analysis (Pérez-Gregorio, Mateus, \& de Freitas, 2014). The registered increases were proportional to the amount of EC in the media, since the higher the concentration of $\mathrm{EC}$, the higher the increase of the total area of the fraction. It is worth noting that the association of EC and salivary proteins leading to soluble complexes could lead to changes in their elution properties. This possibility hinders the assignment of any protein family to the formation of soluble complexes. To reveal which of the salivary proteins are involved in soluble complexes formation it would be necessary to isolate them and to identify the proteins.

The fractions which presented significant decreases (fractions 3 , 5 and 7) were mainly composed by glycosilated and acidic PRPs, statherin and P-B peptide. The presence of P-B peptide in fractions which show either increase or decrease (fractions 2 and 7, respectively) may indicate that EC interacts preferentially with statherin than with the P-B peptide and that, in presence of statherin, the effect over P-B peptide is not noticeable.

EC has been described as more astringent and bitter than CAT (Ferrer-Gallego et al., 2015; Kallithraka et al., 1997; Peleg et al., 1999; Thorngate \& Noble, 1995) and the astringency perception is described as more persistent in the case of EC (Ferrer-Gallego et al., 2014; Thorngate \& Noble, 1995). This higher persistence could be related to the formation of both soluble and insoluble complexes, since the formation of soluble complexes has been hypothesized as an intermediary step in the formation of insoluble aggregates (Jobstl, O'Connell, Fairclough, \& Williamson, 2004). Moreover, regarding astringency sub-qualities, EC presented higher values for descriptors such as unripe, harsh and drying, which are commonly considered as "unpleasant" sensations (Ferrer-Gallego et al., 2014). The different intensity of these attributes perception for CAT and EC could be related to the different proteins involved in the interaction with those compounds.

\subsubsection{Gallocatechin}

In contrast to the results observed in CAT and EC assays, in the GC assay slight differences were found between the two times tested, $30 \mathrm{~min}$ and $2 \mathrm{~h}$, which indicates that the interaction with salivary proteins in the case of GC is slower than it is for CAT and EC. This result is in good agreement with the fact that GC has been perceived as less persistent than CAT by panelists (Ferrer-Gallego et al., 2015) and also with molecular dynamic simulation test showing that the interaction of GC with the prolinerich peptide IB $7_{14}$ needed more time to be established than the interaction of the same peptide with CAT, and that it was also less stable.

No significant changes were observed for GC interaction, despite a clear trend was shown for fractions 1 and 3, which presented an increase in their areas and for fraction 6 , which suffered a decrease (Fig. 4). Moreover, as can be seen in Fig. 4 for the twohour assays, peaks 1 and 3 continued to increase their areas, whereas the rest of the peaks showed the same trend than in the 30 min assays. The absence of significant changes may be related to a less intense interaction in the case of GC compared to CAT or EC. This behavior could be related with the perception of GC as less astringent than CAT or EC, since maybe higher concentrations of GC should be present to provoke a significant change in salivary proteins. Moreover, the interaction between GC and salivary proteins seems to be more related to the formation of soluble complexes, causing an increase in the absorbance, than to the precipitation of proteins. Despite the studies leading with gallocatechin or prodelphinidins astringency perception are scarce, they 


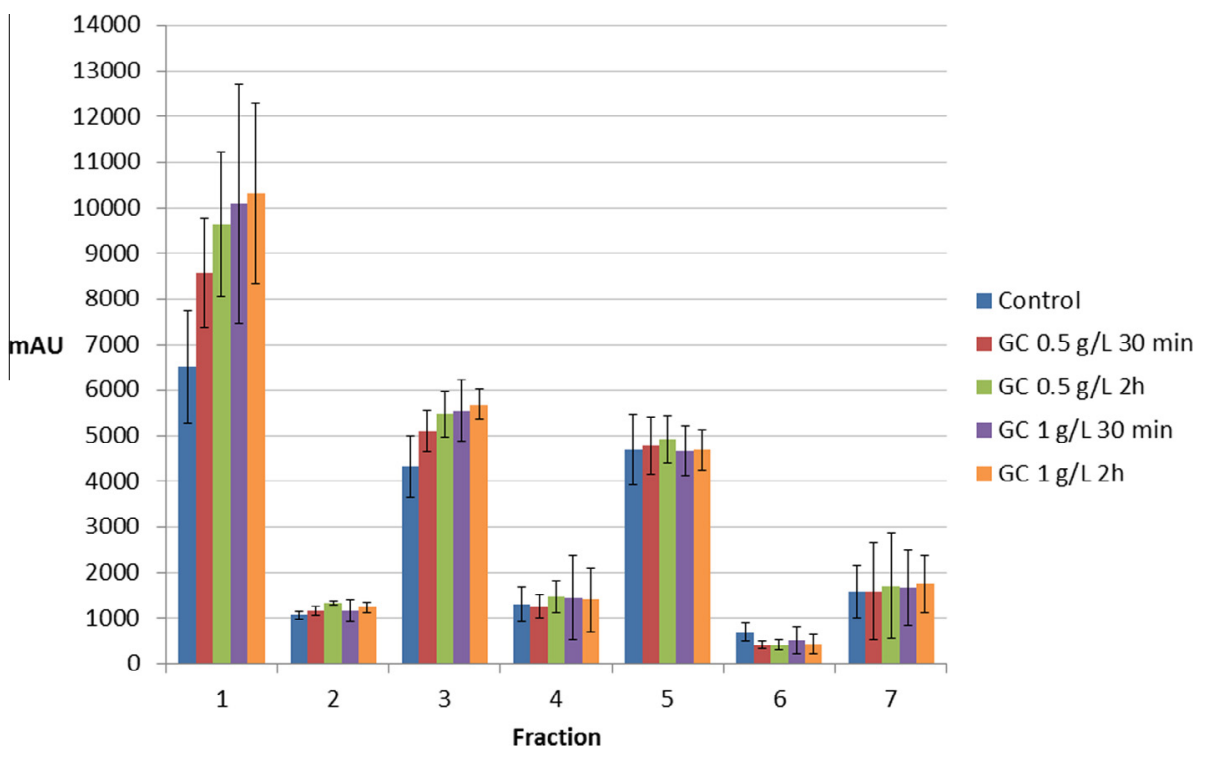

Fig. 4. Chromatographic areas registered at $214 \mathrm{~nm}$ determined for gallocatechin assays.

have been related with a decrease in astringency (Gil et al., 2012) and to better astringency sub-qualities in wines such as richness or roundness (Ferrer-Gallego et al., 2015).

The described method provided the evidence by HPLC-DAD of the existence of soluble complexes formed by the interaction of flavan-3-ols and salivary proteins. This study nicely outlines the possibility of the study of the interactions between flavan-3-ols and salivary proteins not only as a precipitation issue as it has been classically studied, but also as a more complex interaction, which involves the formation of soluble and insoluble complexes and different salivary proteins responses. It also gives information about the groups of proteins and flavan-3-ols involved in each phenomenon, which could be related to the different astringency sub-qualities described by tasters.

\section{Acknowledgements}

The proteomic analysis was performed in the proteomics facility of Centro de Investigación del Cáncer, Salamanca, Spain, that belongs to ProteoRed, PRB2-ISCIII, supported by grant PT13/0001. Thanks are due to the Spanish MICINN (Project ref. AGL201458486-C2-1-R) for financial support.

\section{References}

Brosch, M., Yu, L., Hubbard, T., \& Choudhary, J. (2009). Accurate and sensitive peptide identification with mascot percolator. Journal of Proteome Research, 8 (6), 3176-3181.

Cabras, T., Pisano, E., Boi, R., Olianas, A., Manconi, B., Inzitari, R., ... Messana, I. (2009). Age-dependent modifications of the human salivary secretory protein complex. Journal of Proteome Research, 8(8), 4126-4134.

Cala, O, Dufourc, E. J., Fouquet, E., Manigand, C. Laguerre, M., \& Pianet, I. (2012). The colloidal state of tannins impacts the nature of their interaction with proteins: The case of salivary proline-rich protein/procyanidins binding. Langmuir, 28 (50), 17410-17418.

Cala, O., Fabre, S., Pinaud, N., Dufourc, E. J., Fouquet, E., Laguerre, M., \& Pianet, I. (2011). Towards a molecular interpretation of astringency: Synthesis, 3D structure, colloidal state, and human saliva protein recognition of procyanidins, Planta Medica, 77(11), 1116-1122.

Cala, O., Pinaud, N., Simon, C., Fouquet, E., Laguerre, M., Dufourc, E. J., \& Pianet, I. (2010). NMR and molecular modeling of wine tannins binding to saliva proteins: Revisiting astringency from molecular and colloidal prospects. FASEB Journal, 24(11), 4281-4290.

Castagnola, M., Cabras, T., Vitali, A., Sanna, M. T., \& Messana, I. (2011) Biotechnological implications of the salivary proteome. Trends in Biotechnology, 29(8), 409-418.

Chira, K., Schmauch, G., Saucier, C., Fabre, S., \& Teissedre, P. L. (2009). Grape variety effect on proanthocyanidin composition and sensory perception of skin an seed tannin extracts from bordeaux wine grapes (Cabernet Sauvignon and Merlot) for two consecutive vintages (2006 and 2007). Journal of Agricultural and Food Chemistry, 57(2), 545-553.

Dawes, C. (1972). Circadian-rhythms in human salivary flow-rate and composition. Journal of Physiology-London, 220(3). 529-\&.

de Freitas, V., \& Mateus, N. (2012). Protein/polyphenol interactions: Past and present contributions. Mechanisms of astringency perception. Current Organic Chemistry, 16(6), 724-746.

Ferrer-Gallego, R. Gonçalves, R., Rivas-Gonzalo, J. C., Escribano-Bailón, M. T., \& de Freitas, V. (2012). Interaction of phenolic compounds with bovine serum albumin (BSA) and alpha-amylase and their relationship to astringency perception. Food Chemistry, 135(2), 651-658.

Ferrer-Gallego, R., Hernández-Hierro, J. M. Rivas-Gonzalo, J. C. \& Escribano-Bailón, M. T. (2014). Sensory evaluation of bitterness and astringency sub-qualities of wine phenolic compounds: Synergistic effect and modulation by aromas. Food Research International, 62, 1100-1107.

Ferrer-Gallego, R., Quijada-Morín, N., Brás, N. F., Gomes, P., de Freitas, V., RivasGonzalo, J. C., \& Escribano-Bailón, M. T. (2015). Characterization of sensory properties of flavanols - A molecular dynamic approach. Chemical Senses, 40(6), 381-390.

Gawel, R. (1998). Red wine astringency: A review. Australian Journal of Grape and Wine Research, 4(2), 74-95.

Gibbins, H. L., \& Carpenter, G. H. (2013). Alternative mechanisms of astringency What is the role of saliva? Journal of Texture Studies, 44(5), 364-375.

Gil, M., Kontoudakis, N., González, E., Esteruelas, M., Fort, F., Canals, J. M., \& Zamora, F. (2012). Influence of grape maturity and maceration length on color, polyphenolic composition, and polysaccharide content of Cabernet Sauvignon and Tempranillo wines. Journal of Agricultural and Food Chemistry, 60(32), $7988-8001$

Hagerman, A. E. (1992). Tannin protein interactions. ACS Symposium Series, 506, $236-247$.

Ishihama, Y., Oda, Y., Tabata, T., Sato, T., Nagasu, T., Rappsilber, J., \& Mann, M. (2005). Exponentially modified protein abundance index (emPAI) for estimation of absolute protein amount in proteomics by the number of sequenced peptides per protein. Molecular \& Cellular Proteomics, 4(9), 1265-1272.

Jiang, Y., Gong, N. N., \& Matsunami, H. (2014). Astringency: A more stringent definition. Chemical Senses, 39(6), 467-469.

Jobstl, E., O'Connell, J., Fairclough, J. P. A., \& Williamson, M. P. (2004). Molecular model for astringency produced by polyphenol/protein interactions. Biomacromolecules, 5(3), 942-949.

Kallithraka, S., Bakker, J., \& Clifford, M. N. (1997). Evaluation of bitterness and astringency of $(+)$-catechin and (-)-epicatechin in red wine and in model solution. Journal of Sensory Studies, 12(1), 25-37.

Kallithraka, S., Bakker, J., \& Clifford, M. N. (1998). Evidence that salivary proteins are involved in astringency. Journal of Sensory Studies, 13(1), 29-43.

Link, A. J., Eng, J., Schieltz, D. M., Carmack, E., Mize, G. J., Morris, D. R., ... Yates, J. R. (1999). Direct analysis of protein complexes using mass spectrometry. Nature Biotechnology, 17(7), 676-682.

Ma, W., Guo, A., Zhang, Y., Wang, H., Liu, Y., \& Li, H. (2014). A review on astringency and bitterness perception of tannins in wine. Trends in Food Science \& Technology, 40(1), 6-19.

Messana, I., Cabras, T., Inzitari, R., Lupi, A., Zuppi, C., Olmi, C., ... Castagnola, M. (2004). Characterization of the human salivary basic proline-rich protein complex by a proteomic approach. Journal of Proteome Research, 3(4), 792-800. 
Monagas, M., Gómez-Cordovés, C., Bartolomé, B., Laureano, O., \& Ricardo-Da-Silva, J. M. (2003). Monomeric, oligomeric, and polymeric flavan-3-ol composition of wines and grapes from Vitis vinifera L. cv. Graciano, Tempranillo, and Cabernet Sauvignon. Journal of Agricultural and Food Chemistry, 51(22), 6475-6481.

Olsen, J. V., de Godoy, L. M. F. Li, G. Q. Macek, B., Mortensen, P., Pesch, R. ... Mann, M. (2005). Parts per million mass accuracy on an orbitrap mass spectrometer via lock mass injection into a C-trap. Molecular \& Cellular Proteomics, 4(12), 2010-2021.

Peleg, H., Gacon, K., Schlich, P., \& Noble, A. C. (1999). Bitterness and astringency of flavan-3-ol monomers, dimers and trimers. Journal of the Science of Food and Agriculture, 79(8), 1123-1128.

Pérez-Gregorio, M. R., Mateus, N., \& de Freitas, V. (2014). Rapid screening and identification of new soluble tannin-salivary protein aggregates in saliva by mass spectrometry (MALDI-TOF-TOF and FIA-ESI-MS). Langmuir, 30(28), 8528-8537.

Perez-Maldonado, R. A., Norton, B. W., \& Kerven, G. L. (1995). Factors affecting invitro formation of tannin-protein complexes. Journal of the Science of Food and Agriculture, 69(3), 291-298.

Perkins, D. N., Pappin, D. J. C., Creasy, D. M., \& Cottrell, J. S. (1999). Probability-based protein identification by searching sequence databases using mass spectrometry data. Electrophoresis, 20(18), 3551-3567.

Sarni-Manchado, P., Canals-Bosch, J.-M., Mazerolles, G., \& Cheynier, V. (2008). Influence of the glycosylation of human salivary proline-rich proteins on their interactions with condensed tannins. Journal of Agricultural and Food Chemistry, 56(20), 9563-9569.

Schwarz, B., \& Hofmann, T. (2008). Is there a direct relationship between ora astringency and human salivary protein binding? European Food Research and Technology, 227(6), 1693-1698.

Scollary, G. R., Pasti, G., Kallay, M., Blackman, J., \& Clark, A. C. (2012). Astringency response of red wines: Potential role of molecular assembly. Trends in Food Science \& Technology, 27(1), 25-36.

Soares, S., Vitorino, R., Osorio, H., Fernandes, A., Venancio, A., Mateus, N., ... de Freitas, V. (2011). Reactivity of human salivary proteins families toward food polyphenols. Journal of Agricultural and Food Chemistry, 59(10), 5535-5547.

Sun, B. de Sa, M., Leandro, C. Caldeira, I., Duarte, F. L. \& Spranger, I. (2013). Reactivity of polymeric proanthocyanidins toward salivary proteins and their contribution to young red wine astringency. Journal of Agricultural and Food Chemistry, 61(4), 939-946.

Thorngate, J. H., \& Noble, A. C. (1995). Sensory evaluation of bitterness and astringency of 3R(-)-Epicatechin and 3S(+)-Catechin. Journal of the Science of Food and Agriculture, 67(4), 531-535.

Wollmann, N., \& Hofmann, T. (2013). Compositional and sensory characterization of red wine polymers. Journal of Agricultural and Food Chemistry, 61(9), 2045-2061.

Wu, A. M., Csako, G., \& Herp, A. (1994). Structure, biosynthesis, and function of salivary mucins. Molecular and Cellular Biochemistry, 137(1) 39-55. 